\title{
Inhibition of COX-2 Aggravates Neutrophil Migration and Pneumocyte Apoptosis in Surfactant-Depleted Rat Lungs
}

\author{
HEIKKI LUKKARINEN, JUKKA LAINE, HEIKKI AHO, EEVA ASIKAINEN, PAULIINA PENTTINEN, AND PEKKA KÄÄPÄ \\ Research Centre of Applied and Preventive Cardiovascular Medicine (CAPC) [H.L., E.A., P.P., P.K.], Department of Pathology \\ [J.L., H.A.], Department of Pediatrics [P.K.], University of Turku, FIN-20520 Turku, Finland
}

\begin{abstract}
Pulmonary inflammation and parenchymal apoptosis are implicated in the pathogenesis of the acute lung injury, but the mechanisms of these reactions are still unclear. Because inhibition of the proinflammatory cyclo-oxygenase (COX)-2 enzyme action is proposed to be useful in various inflammatory lung injuries, we decided to investigate the expression of COX-2 and the possible beneficial effects of its inhibition on pulmonary inflammation and apoptosis in surfactant-depleted lungs. The injury was induced in 2-mo-old rats by repeated lung lavage to remove alveolar surfactant. Eight of these rats were pretreated with a specific COX-2 inhibitor, NS-398. All rats, including control rats without lung lavage, were ventilated with $60 \%$ oxygen for $5 \mathrm{~h}$, and the lungs were then studied histologically for tissue injury and with DNA nick-end labeling, cleaved caspase-3 immunohistochemistry, and electron microscopy for apoptotic cell death. Lung tissue myeloperoxidase activity and the expression of COX-2 protein and concentration of prostaglandin $\mathrm{E}_{2}$ were additionally analyzed. Lung lavage increased pulmonary neutrophil migration, histologic injury, and the occurrence of epithelial apoptosis. In contrast, expression of COX-2 and amount of $\mathrm{PGE}_{2}$ were significantly lower in surfactant-depleted lungs than controls. Pretreatment with the COX-2 inhibitor further increased the migration of neutrophils and occurrence of epithelial apoptosis in the surfactant-depleted lungs, compared with nontreated insulted lungs. These results suggest that specific inhibitors of COX-2 should be used cautiously in association with surfactant-deficient lung injuries. (Pediatr Res 59: 412-417, 2006)
\end{abstract}

$\mathrm{S}^{\mathrm{e}}$ evere acute lung injuries in newborns and adults are often manifested in critical hypoxemia and respiratory failure with high mortality and morbidity. The pathogenetic processes leading to these perturbations are generally associated with necrotic inflammatory destruction and surfactant insufficiency in the lungs, but the mechanisms of the pulmonary damages are complex and still poorly understood $(1,2)$. Recently, apoptosis, a noninflammatory type of cell destruction, has also been connected to the pathophysiology of acute lung injuries from various causes $(3,4)$. In acute diffuse injury in neonatal and adult lungs, the primary targets of cell death processes are especially the alveolar epithelial cells, including type II pneu-

Received February 14, 2005; accepted November 2, 2005.

Correspondence: Heikki Lukkarinen, M.D., Ph.D., Research Centre of Applied and Preventive Cardiovascular Medicine (CAPC), University of Turku, FIN-20520 Turku, Finland; e-mail: heikki.lukkarinen@utu.fi

This study is financially supported by the Turku University Hospital, the Finnish Cultural Foundation, the Sigrid Juselius Foundation, the Pediatric Research Foundation, the Paulo Foundation, and Turku University Foundation, Finland. mocytes $(5,6)$. Because normal structure and function of the epithelial barrier is critical for the maintenance of alveolar fluid balance and surfactant synthesis and secretion, inflammatory and apoptotic epithelial cell death may be of significance in acute respiratory disorders of neonates and adults $(5,7)$. Although activation of pulmonary inflammatory cells and release of various cytokines are proposed to promote inflammation and also apoptosis in the lungs, the mediating mechanisms and interplay of these processes in the development of lung injury have thus far remained unclear.

Prostanoids have been implicated as important mediators of various pathologic processes, including inflammation (8). The rate-limiting step in prostaglandin biosynthesis is the conversion of arachidonic acid to endoperoxides by cyclooxygenase enzymes, known to exist in two isoforms. The activity of the constitutive cyclooxygenase-1 (COX-1) is usually stable, whereas cyclooxygenase-2 (COX-2) activity can be stimulated by various endogenous or exogenous proinflammatory substances in a wide variety of cell types $(8,9)$. In the lungs, COX-2 is up-regulated in response to pro-inflammatory cytokines and after endotoxin or meconium challenge $(10,11)$. Selective expression of COX-2 in stimulated alveolar macrophages results in increased production of prostanoids with various pathophysiological effects in the lung, e.g. edema formation, implying a role for COX-2 in the development of acute inflammatory lung injury $(10,12)$. Although inhibition of COX-2 is thus supposed to reduce the inflammatory injury in the lungs, studies with specific COX-2 and unspecific COX inhibitors have produced conflicting results (13-15). Recently, COX-2 expression is additionally connected to apoptotic cell death in lung epithelium, especially after neoplastic transformation $(13,14)$. There is still, however, scanty information on the role of COX-2 expression in the development of apoptosis associated with acute lung injury. We hypothesized that pulmonary COX-2 expression is increased and may thereby contribute to intensified inflammatory reaction, restricted apoptosis, and sustained epithelial damage in acutely insulted

Abbreviations: COX-2, cyclo-oxygenase 2; NS-398, N-[2-(cyclohexyloxy)4-nitrofenyl]-methane sulfonamide; TUNEL, terminal deoxynucleotidyl transferase-mediated nick end-labeling

DOI: 10.1203/01.pdr.0000200798.79840.3d 
lungs, and thus decided to investigate the expression of COX-2 protein and the possible beneficial effects of its specific inhibition in surfactant-depleted rat lungs.

\section{METHODS}

Animal preparation. Thirty-nine 2-mo-old male Sprague-Dawley rats (mean weight, $320 \mathrm{~g} ;$ SD $150 \mathrm{~g}$ ) were anesthetized with a mixture of fentanyl-fluanisone $(0.4 \mathrm{~mL} / \mathrm{kg}$, Hypnorm, Janssen Pharmaceutica, Antwerp, Belgium) and midazolam (0.4 mL/kg, Dormicum, Roche, Espoo, Finland) intraperitoneally, intubated through tracheostomy, and ventilated with a pressure-controlled respirator (Baby-Bird, Bird Corp., Palm Springs, CA) (frequency, $30 / \mathrm{min}$; peak inspiratory pressure, $25 \mathrm{cmH}_{2} \mathrm{O}$; end-expiratory pressure, $5 \mathrm{cmH}_{2} \mathrm{O}$ ). Anesthesia was maintained by continuous intraperitoneal infusion of Hypnorm $(0.2 \mathrm{mg} / \mathrm{h})$. The experiments were approved by the Committee of Animal Care in Research of the University of Turku.

Lung injury. Alveolar surfactant was removed by three repeated lavages of the lungs with $6 \mathrm{~mL}$ of sterile saline through the endotracheal tube in 16 rats. All these animals were ventilated with $60 \%$ oxygen for $5 \mathrm{~h}$. Eight rats with no lung insult were similarly ventilated with $60 \%$ oxygen for $5 \mathrm{~h}$ and served as controls. In addition, to investigate the possible pulmonary effects of inspired $60 \%$ oxygen, eight rats with no intratracheal instillation were ventilated with room air for $5 \mathrm{~h}$. At the end of the experiment, a blood sample was taken by a direct puncture of the left cardiac ventricle for blood gas analysis and the animals were then euthanized. After thoracotomy, the lungs were perfused with $10 \mathrm{~mL}$ of saline through a pulmonary artery catheter, and lung tissue samples were obtained for the measurement of the wet/dry weight ratio as well as histologic and biochemical analysis.

COX-2 inhibition. A separate group of rats with lavaged lungs received an intraperitoneal injection ( $1 \mathrm{~mL}$ ) of a specific COX-2 inhibitor NS-398 (Sigma Chemical Co., St. Louis, MO; $2 \mathrm{mg} / \mathrm{mL} ; 3 \mathrm{mg} / \mathrm{kg}, n=8$ ) diluted in DMSO 30 min before the insult. At this dose, NS-398 has been previously shown to be COX-2 selective (16). The possible pulmonary effects of the intraperitoneally administered vehicle of NS-398 (DMSO) were tested in three of the control rats, but no lung alterations were found (data not shown). Likewise, an additional group of four nonlavaged rats ventilated with $60 \%$ oxygen received $1 \mathrm{~mL}$ of NS-398 intraperitoneally. All the rats were ventilated for $5 \mathrm{~h}$ and treated as above, and the lungs were similarly studied at the end of the study.

Histologic examination. Pulmonary tissue samples from the right lower lobe were fixed in $10 \%$ buffered formalin, embedded in paraffin, and stained with hematoxylin and eosin for the determination of the severity of lung injury. Samples were assessed by a pathologist blinded to the grouping of the rats. A score from 0 to 4 represented the percentile of affected area of the lung section $(0=0 \% ; 1=1-25 \% ; 2=26-50 \% ; 3=51-75 \% ; 4=76-100 \%)$ and was assigned for three different characteristics: 1) extension of pulmonary leukocyte infiltration, 2) amount of intraalveolar leukocytes, and 3) amount of exudative debris and edema fluid. The calculated total injury score represents the sum of these scores $(17,18)$.

Myeloperoxidase activity. As a measure of pulmonary neutrophil influx, tissue specimens of the lungs were initially frozen and later measured for myeloperoxidase (MPO) activity. After homogenization of the tissue, MPO activity was assayed spectrophotometrically using a method in which the enzyme catalyses the oxidation of 3,3',5,5'-tetramethylbenzidine by $\mathrm{H}_{2} \mathrm{O}_{2}$ to yield a blue chromogen with a maximum wavelength of $655 \mathrm{~nm}(17-19)$. The results were related to the wet/dry ratio and expressed as units per milligram of protein.

Western blot analysis of COX-2. Frozen lung samples were gently homogenized in protein extraction buffer [5.0 ml 0.3 M Tris-HCL, pH 8; $870 \mu \mathrm{l}$ $10 \mathrm{mg} / \mathrm{ml}$ phenylmethyl sulfonyl fluoride (PMSF); and $5.0 \mathrm{ml} \mathrm{10 \%} \mathrm{sodium}$ dodecyl (lauryl) sulphate (SDS)]. After removal of the cell debris by centrifugation, protein homogenate was added to SDS-PAGE loading buffer and heated for $5 \mathrm{~min}$ at $97^{\circ} \mathrm{C}$. Samples were then run on a $10 \%$ SDSpolyacrylamide gels. Western blotting was performed according to the ECL Western blotting protocol (Amersham Life Sciences, Little Chalfont, Buckinghamshire, UK). COX-2 was detected with a rabbit anti-murine polyclonal antibody (Cayman Chemical, Ann Arbor, MI), diluted at 1:2000. The antibody identified the COX-2 $(\sim 72 \mathrm{kD})$. Binding of primary antibody was detected with horseradish peroxidase-conjugated goat anti-rabbit immunoglobulins (diluted at 1:5000). Identity of the expressed proteins was determined by the expected size of the product on the membranes. The data of the COX-2 was normalized against the housekeeping protein $\beta$-actin (Sigma Chemical Co.).

Prostaglandin $\boldsymbol{E}_{2}$ enzyme immunoassay (EIA). As an indicator of COX-2 activation, the amount of the catalyzed end-product bicycle-prostaglandin $\mathrm{E}_{2}$ was analyzed with enzyme immunoassay. Briefly, frozen lung sections from the right upper lobe were homogenized in EIA buffer (Cayman Chemical). After removal of the cell debris by centrifugation, concentration of the protein homogenate was analyzed spectrophotometrically in Bradford solution. Samples were then diluted 1:10 or 1:20 in EIA Buffer and analyzed with Bicyclo-prostaglandin $\mathrm{E}_{2}$ enzyme immunoassay kit (Cayman Chemical) according to the manufacturer's recommendations. Absorbance reading was finally normalized with the total protein concentration of the samples.

In situ detection of apoptotic cells (TUNEL). Terminal transferase mediated DNA nick end-labeling assay was performed in paraffin wax sections, as described earlier $(17,18,20)$. Lymphocytes undergoing apoptosis in the lymph nodes served as a positive control. Apoptotic cells were counted in lung sections stained with the antidigoxigenin antibody. A distinct color reaction within the cells was regarded to represent apoptotic DNA fragmentation. The results are expressed as the number of positive cells per $\mathrm{mm}^{2}$ of tissue section area in at least 10 fields of view of a $\times 10$ objective lens. The in situ detection of free DNA 3' ends is a well-established method in the detection of apoptotic cellular changes in pneumocytes (21).

Identification of apoptosis in the epithelial cells. To identify the occurrence of apoptosis in the pulmonary epithelium, thin $(3 \mu \mathrm{m})$ consecutive sections of paraffin-embedded lung tissue samples were studied. The first section was pretreated with pepsin and stained with a monoclonal mouse antibody MNF-116 (Dakopatts, Glostrup, Denmark), which recognizes type-II epithelial cells $(22,23)$. Briefly, the sections were blocked with Trisbuffered saline (TBS) containing $1 \mathrm{mg} / \mathrm{mL}$ BSA (TBS/BSA) for $30 \mathrm{~min}$ and incubated with the antibody, diluted 1:10 in TBS, for $30 \mathrm{~min}$. After incubation, the sections were washed three times with TBS and stained with the secondary antibody. The second section was stained with the TUNEL method for the detection of the DNA fragmentation in apoptotic cells, as described above. Apoptosis was identified in the epithelium by comparing the staining of the cells in successive sections.

Cleaved caspase-3 staining. To evaluate the occurrence of proapoptotic caspase- 3 in the respiratory tract, separate sections of the lungs were stained with a cleaved caspase-3 antibody (Asp175, Cell Signaling Technology, Beverly, MA). Formalin-fixed paraffin-embedded sections were prepared and processed according to the manufacturer's recommendations with slight modifications. Briefly, deparaffinized sections were pretreated by $0.4 \%$ pepsin in $\mathrm{HCl}(0.01 \mathrm{M})$ for $1 \mathrm{~h}$ at $37^{\circ} \mathrm{C}$ in a humidified chamber. Endogenous peroxidases were blocked with $0.3 \% \mathrm{H}_{2} \mathrm{O}_{2}$ for $20 \mathrm{~min}$ and the sections were incubated with primary antibody overnight at room temperature. Sections were then washed with TBS and incubated with biotinylated rabbit antimouse Ig (DAKO A/S, Glostrup, Denmark) followed by streptavidin-HRP (Roche Molecular Biochemicals). Sections were finally visualized with diaminobenzidine (DAB) and counterstained with hematoxylin. To evaluate the amount of positive staining, the lung sections were semiquantitatively analyzed in the light microscopy and further positively stained lung areas were compared with TUNEL-positive areas.

Electron microscopy. Small pieces of lung tissue $\left(1 \mathrm{~mm}^{3}\right)$ from the right lower lobe were obtained for ultrastructural analysis of the alveolocapillary injury and apoptotic pulmonary cell death with electron microscopy, as described earlier (24).

Statistical analysis. The results are expressed as means (SD). One-way ANOVA was used to compare the data in different groups. If the overall ANOVA was significant, comparisons between the groups were made using Tukey's posthoc test. The relationship between the number of apoptotic cells and MPO activity within each case was evaluated using Pearson correlation. A level of $p<0.05$ was considered statistically significant.

\section{RESULTS}

Repeated lung lavage resulted in a decrease in arterial $\mathrm{Po}_{2}$ and base excess, and increase in lung tissue wet/dry ratio, compared with controls, but no hypoxemic values were recorded at the end of the study period (Table 1). Ventilation of the control rats with room air produced higher $\mathrm{pH}$ and lower arterial $\mathrm{PO}_{2}$ values, but similar wet/dry ratios than in rats ventilated with $60 \%$ oxygen (data not shown). Further, in the lavaged lungs, leukocyte accumulation and the amount of alveolar exudate, and consequently also the histologic injury score, were significantly higher than in controls at $5 \mathrm{~h}$ after the insult (Table 2 and Fig. 1). Still, the MPO activity in the insulted lungs did not differ statistically from the control level (Table 2). Ventilation of undamaged lungs with air for $5 \mathrm{~h}$, 
Table 1. Arterial pH, blood gases, and lung tissue wet/dry ratio in rats with repeated lung lavage with (LAV+NS398) or without (LAV) COX-2 blockade, and controls $(C)$ after 5 hentilation

\begin{tabular}{lcccccc}
\hline & No. & $\mathrm{pH}$ & $\mathrm{PO}_{2}(\mathrm{kPa})$ & $\mathrm{PCO}_{2}(\mathrm{kPa})$ & $\mathrm{ABE}(\mathrm{mmol} / \mathrm{L})$ & wet/dry ratio \\
\hline $\mathrm{C}$ & 8 & $7.33(0.11)$ & $29.6(10.0)$ & $4.6(2.3)$ & $-6.6(4.2)$ & $3.8(0.3)$ \\
$\mathrm{LAV}$ & 8 & $7.23(0.11)$ & $14.7(8.7)^{*}$ & $3.8(1.6)$ & $-14.6(7.0)^{*}$ & $6.1(2.0)^{*}$ \\
$\mathrm{LAV}+\mathrm{NS} 398$ & 8 & $7.43(0.13) \dagger$ & $23.6(14.3)$ & $4.3(1.3)$ & $-2.8(2.5) \dagger$ & $7.2(0.5)^{*}$ \\
\hline
\end{tabular}

Data given as mean (SD).

$* p<0.05 v s$ control, $\dagger p<0.05$ vs lavage.

compared with $60 \%$ oxygen ventilation, did not affect the histologic injury (data not shown).

The number of TUNEL-positive cells, indicating the presence of apoptotic cell death, was increased in the lavaged lungs when compared with controls (Figs. 2 and 3). Positive parenchymal cell staining of cleaved caspase- 3 in the lavaged lungs further supported this finding (Fig. 4). Electron microscopic studies (20) and staining of consecutive lung sections with TUNEL (Fig. 5A) and MNF-116 antibody (Fig. 5B) further demonstrated that apoptotic cell death was mainly located in the respiratory epithelium, including type II pneumocytes. Ventilation of the control lungs with air for $5 \mathrm{~h}$ did not affect the TUNEL-positivity [air ventilated: mean 3.59 TUNEL-positive cells $/ \mathrm{mm}^{2}$ (SD 1.78) versus oxygen ventilated: 3.13 (1.80)]. Expression of the lung tissue COX-2 protein was significantly down-regulated in the lavaged lungs compared with control (Fig. 6A). Similarly, PGE2 production in the insulted lungs was also significantly lowered from the control level (Fig. 6B).

Pretreatment with the COX-2 antagonist NS-398 did not change the arterial blood gases, wet/dry ratio, histologic injury score, or the number of TUNEL-positive cells from the control level in the oxygen-ventilated, nonlavaged rats (data not shown). However, NS-398 pretreatment resulted in higher arterial $\mathrm{pH}$ and base excess than after lavage without any pretreatment, but did not significantly affect arterial $\mathrm{Po}_{2}, \mathrm{PCO}_{2}$, or tissue wet/dry ratio in the lavaged lungs (Table 1). On the other hand, NS-398 pretreatment significantly increased the leukocyte accumulation and histologic injury score in the lavaged lungs compared with nontreated injured lungs (Table 2). Similarly, NS-398 administration also resulted in significantly elevated lung tissue MPO activity from the control level (Table 2). The pulmonary leukocyte accumulation was also confirmed with Leder-staining (Fig. 1). Furthermore, the number of TUNEL-positive pulmonary epithelial cells was significantly elevated in the NS-398-pretreated lavaged lungs compared with nontreated damaged lungs (Figs. 2 and 3). Expression of COX-2 protein was decreased in pretreated surfactant-depleted lungs compared with controls (Fig. 6A), but did not significantly differ from the nontreated, surfactantdepleted lungs. Similarly, the already decreased production of $\mathrm{PGE}_{2}$ in the lavaged lungs did not significantly change after NS-398 pretreatment (Fig. 6B).

\section{DISCUSSION}

COX-2 is an early response gene that is up-regulated and suggested to promote acute inflammatory processes in various insulted organs, including the lungs $(25,26)$. Consequently, there is a bulk of data indicating that selective inhibition of COX-2 expression should be the main target for the treatment of inflammatory diseases $(9,27)$. By contrast, we show here evidence that COX-2 is not up-regulated in acute lung injury accompanied by surfactant deficiency and that selective blockade of COX-2 enzyme rather enhances leukocyte accumulation and tissue injury, as well as pneumocyte apoptosis than reduces the damage in the surfactant-depleted lungs. Although these data are in line with earlier studies on neoplastic lung tissues $(13,14)$ and cardiac injury models $(28)$, we cannot totally exclude some influence of COX-1 activity on our results, especially because both $\mathrm{COX}-1$ and $\mathrm{COX}-2$ isoforms are expressed in normal rat lung (29). Therefore, even though NS-398 at a dose used in the present study is shown to be a selective inhibitor of COX-2 (16), our results clearly demonstrate that further careful evaluation of the importance of COX-2 expression in acute lung injury is warranted.

Various forms of acute inflammatory lung injuries, like ischemia/reperfusion, acid aspiration, and endotoxin or meconium challenge, are associated with pulmonary overexpression of COX-2 (29-31). This COX-2 up-regulation, apparently induced by proinflammatory cytokines, with the consequent pulmonary release of prostaglandins and accumulation of polymorphonuclear leukocytes together with edema formation becomes evident within a few hours after the injury (31). Still, the definitive pathogenetic role of these pulmonary responses in the development of inflammatory lung injury has

Table 2. Histological analysis and MPO activity of the lung tissue samples obtained from lavaged rats with (LAV+NS398) or without (LAV) COX-2 inhibition or noninjured $(C)$ rats after 5 h of ventilation

\begin{tabular}{lclllcc}
\hline & No. & $\begin{array}{l}\text { Leukocyte } \\
\text { infiltration }\end{array}$ & $\begin{array}{c}\text { Intraalveolar } \\
\text { leukocytes }\end{array}$ & $\begin{array}{c}\text { Alveolar } \\
\text { exudate }\end{array}$ & $\begin{array}{c}\text { Total injury } \\
\text { score }\end{array}$ & $\begin{array}{c}\text { MPO } \\
\text { (units/mg protein) }\end{array}$ \\
\hline C & 8 & $0.3(0.5)$ & $0.3(0.5)$ & $1.0(0.6)$ & $1.5(1.3)$ & $14.2(5.0)$ \\
LAV & 8 & $1.3(0.5)^{*}$ & $0.8(0.7)$ & $2.0(0.8)^{*}$ & $4.0(1.5)^{*}$ & $20.8(8.7)$ \\
LAV+NS398 & 8 & $2.3(0.5)^{* \dagger}$ & $1.9(0.6)^{* \dagger}$ & $2.4(0.5)^{*}$ & $6.5(1.2)^{* \dagger}$ & $37.3(17.4)^{*}$ \\
\hline
\end{tabular}

A score from 0 to 4 was assigned for each parameter, as described in "Materials and Methods." Total injury score represents the sum of all these scores. Data given as mean $(\mathrm{SD})$.

$* p<0.05$ vs control, $\dagger p<0.05$ vs lavage. 


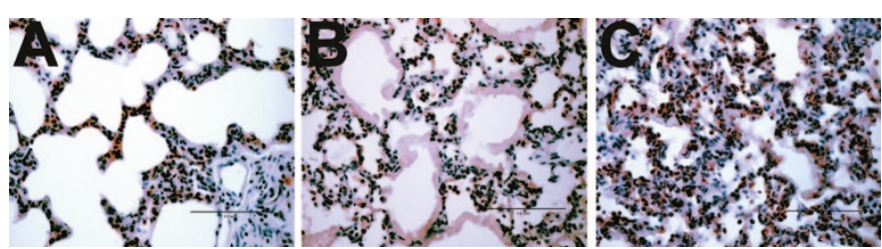

Figure 1. Lung tissue samples obtained after $5 \mathrm{~h}$ ventilation from a control rat $(A)$, surfactant-depleted rat without any pretreatment $(B)$, and from surfactant-depleted rat with specific COX-2 blockade with NS398 pretreatment (C) showing increased lung leukocyte infiltration and tissue injury in the surfactant-depleted rat with COX-2 inhibition (Leder-staining, $\times 260$ ).

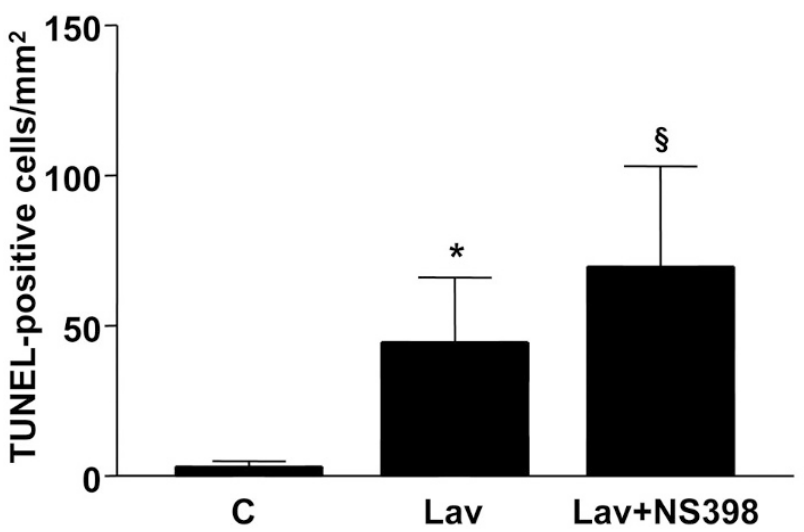

Figure 2. The effect of specific COX-2 blockade with NS398 pretreatment on the number of TUNEL-positive cells $/ \mathrm{mm}^{2}$, potentially indicating apoptosis, in lung sections obtained after lung lavage and $5 \mathrm{~h}$ ventilation (mean, $\mathrm{SD}$ ). $\mathrm{C}=$ control $(n=8)$, Lav $=$ surfactant depletion without any pretreatment $(n=8)$, Lav+NS398 = surfactant depletion with specific COX-2 inhibitor NS398 pretreatment $(n=8)$. $* p<0.01$ vs $\mathrm{C}, \S p<0.05$ vs $\mathrm{C}$ and Lav

remained thus far unsolved, especially since COX-2 may also have antiinflammatory and organ injury-limiting properties (31-33). $\mathrm{PGE}_{2}$, produced through COX-2 activity and commonly considered as a potent proinflammatory mediator (12), also has significant inflammation-limiting and antifibrotic functions in the lungs (34). In fact, this prostaglandin may diminish the release of inflammatory cytokines in vitro and in vivo and also inhibit neutrophil functions, including chemotaxis and oxygen radical production $(8,12)$. In the surfactantdepleted lungs in the present study, COX-2 activity was down-regulated together with diminished production of $\mathrm{PGE}_{2}$, which may thus, at least in part, explain the augmented inflammatory injury in our injury model. Because $\mathrm{PGE}_{2}$ is the predominant cyclooxygenase metabolite of arachidonic acid in the alveolar epithelial cells, damage to the epithelium may result in diminished COX activity and synthesis of $\mathrm{PGE}_{2}$, and thereby in loss of capacity to limit inflammation and ultimately even lead to fibrotic changes (34). Due to the complex pathophysiological role of COX-2 in the insulted lungs, however, the mechanisms and functional significance of reduced COX-2 expression in inflammatory lung disorders associated with surfactant deficiency still remains uncertain.

Whereas the primary observed lesions in surfactantdeficient lungs are proposed to be inflammatory necrotic changes in the respiratory epithelium (35), our present experimental data indicate that the alveolar exudative damage is accompanied by marked pneumocyte apoptosis in the pulmonary tissue. This finding is in line with our recent similar

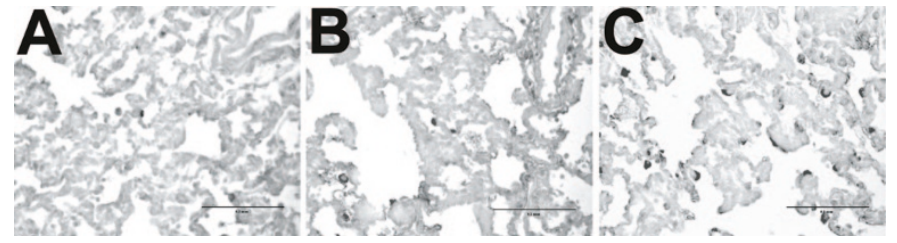

Figure 3. TUNEL-positive cells in the lung tissue. $(A)$ control, $(B)$ surfactantdepleted lung without any pretreatment, $(C)$ surfactant-depleted lung and NS398 pretreatment showing increased TUNEL-positive parenchymal cells in the surfactant-depleted rat with COX-2 inhibition. Dark staining represents DNA-fragmentation $(\times 260)$.

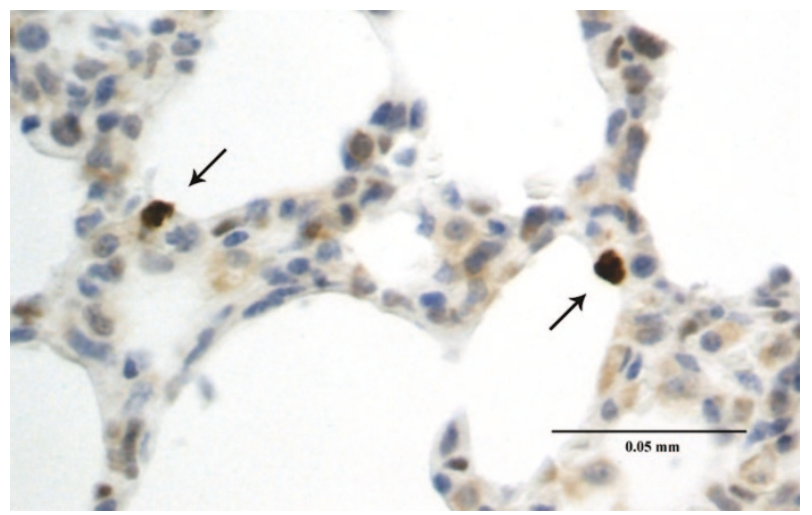

Figure 4. Cleaved caspase-3-positive cells in the alveolar cells of the lavaged lungs with NS398 pretreatment. Arrows indicate the positive staining $(\times 360)$.

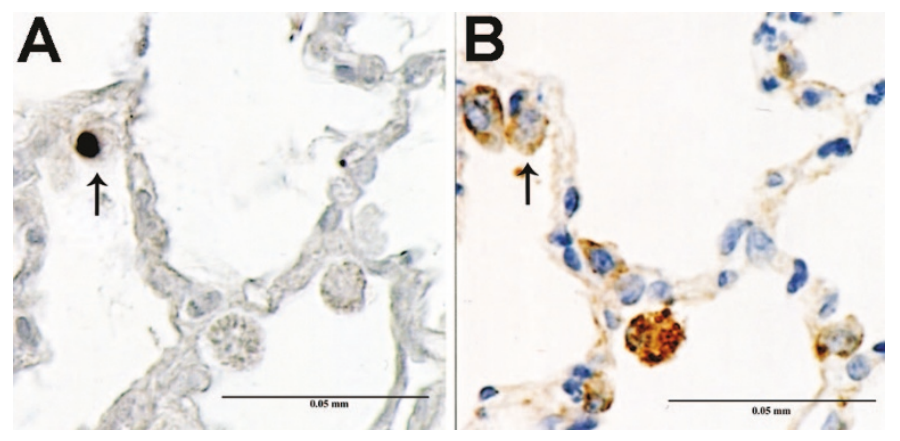

Figure 5. Consecutive sections of lavaged lungs with NS398 pretreatment stained with TUNEL-method $(A)$ and a type-II pneumocyte specific antibody MNF-116 $(B)$. The arrows show the positive staining in the same cell of both sections $(\times 520)$.

observation in the lungs of newborn infants with fatal respiratory distress syndrome and also meconium-induced injury in the rat lungs $(17,18)$. The quantitative analysis of apoptotic cell death in our present study was made with the DNA TUNEL method. Although the TUNEL assay supposedly labels not only apoptotic cells but also random DNA strand breaks in necrotic cells, positive TUNEL staining in our investigation was absent in cells displaying swelling of the cytoplasm, a feature of necrotic cell death. The appearance of apoptotic cells was further confirmed by morphologic studies, and further, lung areas with positive TUNEL-staining were also positively stained with cleaved caspase-3 immunohistochemistry, shown to be a sensitive method for detection of apoptosis (36). Finally, there are recent data that strongly support the specificity of the TUNEL method in detection of apoptosis in the lungs, induced by a variety of stimuli (21). 

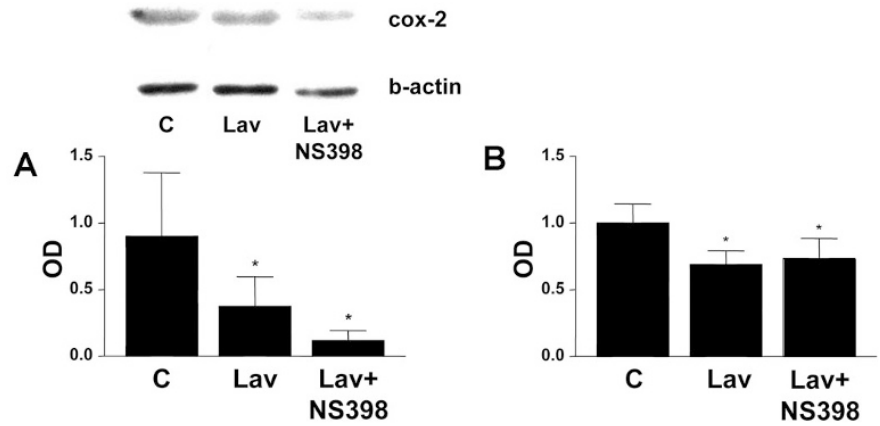

Figure 6. (A) Western blot analysis of COX-2 protein in the lung tissue after $5 \mathrm{~h}$ of ventilation (upper panel). The effect of lung lavage with or without specific COX-2 inhibition with NS398 pretreatment on the expression of COX-2 protein ( $n=8$ in each group) (lower panel). (B) Prostaglandin E2 expression in the same lungs. $\mathrm{C}=$ control, Lav $=$ surfactant depletion, and $\mathrm{Lav}+\mathrm{NS} 398=$ surfactant depletion $+\mathrm{NS} 398$ pretreatment. $* p<0.01$ vs $\mathrm{C}$.

Factors such as Fas or tumor necrosis factor (TNF)- $\alpha$ are suggested to mediate the development of pulmonary apoptotic cell death (4), but the pathogenetic significance of these mechanisms in the development of apoptosis in acute lung injuries still remains to be solved. COX-2 expression is recently connected with apoptotic cell death as a part of tumor development in the lungs $(13,14)$. In fact, increasing evidence suggest that COX-2 overexpression in neoplastic cells suppresses cellular apoptosis and thereby promotes tumorigenesis in the lungs (37). By contrast, COX-2 up-regulation in cardiac myocytes after an acute insult may induce apoptotic cell death, which is considered as a protective mechanism against further injury $(25,26)$. The corresponding association of COX-2 expression and parenchymal apoptosis in acute lung injuries is, however, still poorly known. In surfactant-depleted lungs, COX-2 was down-regulated and appeared to be associated with increased epithelial apoptosis, especially because COX-2 blockade further aggravated this cell destruction process. It may be thus speculated that, in the normal rat lungs, COX-2 activity has a protective function, which is abolished after surfactant depletion, but this remains to be proven.

In the present study, inhibition of COX-2 expression with a specific inhibitor, NS-398, did not reduce pulmonary edema formation or neutrophil infiltration, but rather aggravated the inflammatory and apoptotic lung injury in the surfactantdeficient lungs. The minor improving effect of this treatment on the systemic acid-base status after lung injury remains, however, unclear. In contrast to our results, lung cytokine and chemokine production and neutrophil migration were not affected by NS-398 pretreatment in endotoxemic mice (15). On the other hand, whereas NS-398 administration in murine pleurisy and acid aspiration models induced an early significant decrease in inflammatory parameters and $\mathrm{PGE}_{2}$ production, the selective COX-2 inhibition resulted in intensified inflammation at a later time point, similar to our results (16). Similarly, our data are in line with earlier studies of cardiac injury, where specific inhibition of COX-2 similarly aggravated tissue injury and apoptosis $(28,38)$. Based on the present data, the mechanisms of the detrimental effect of COX-2 inhibition on pulmonary inflammatory and apoptotic injury remain unclear, and, despite having no effect in control lungs, we cannot totally exclude some nonspecific effects of the drug in lavaged lungs. There are indeed in vivo data in humans indicating that COX inhibitors may augment release of cytokines, like the proinflammatory and proapoptotic TNF- $\alpha$ and the potent chemokine IL-8 (39). There are also data indicating that COX-2 inhibitors may induce apoptosis independent of the COX-2 enzyme (37). Thus, although specific COX-2 inhibitors may be beneficial in acute inflammatory events, our present data suggest that they may, in fact, be deleterious in lung disorders associated with surfactant deficiency. Further investigations on the factual effects of specific COX-2 blockers on the surfactant-deficient lungs in newborns and adults are clearly needed.

In conclusion, COX-2 expression and activity are decreased in surfactant-depleted lungs and its blockade with a specific inhibitor does not reduce the pulmonary damage but, in contrast aggravates leukocyte migration and epithelial apoptosis in the insulted lungs. Thus, caution in the administration of specific COX-2 inhibitors in diseases associated with surfactant-deficient lung injuries is warranted.

Acknowledgment. The authors thank Ms. Tiina Peromaa for her excellent technical assistance.

\section{REFERENCES}

1. Ware LB, Matthay MA 2000 The acute respiratory distress syndrome. N Engl J Med 342:1334-1349

2. Jobe AH, Ikegami M 1998 Surfactant and acute lung injury. Proc Assoc Am Physicians 110:489-495

3. Fine A, Janssen-Heininger Y, Soultanakis RP, Swisher SG, Uhal BD 2000 Apoptosis in lung pathophysiology. Am J Physiol Lung Cell Mol Physiol 279:L423-L427

4. Matute-Bello G, Liles WC, Steinberg KP, Kiener PA, Mongovin S, Chi EY, Jonas M, Martin TR 1999 Soluble Fas ligand induces epithelial cell apoptosis in humans with acute lung injury (ARDS). J Immunol 163:2217-2225

5. Sutherland LM, Edwards YS, Murray AW 2001 Alveolar type II cell apoptosis. Comp Biochem Physiol A Mol Integr Physiol 129:267-285

6. Guinee D Jr., Fleming M, Hayashi T, Woodward M, Zhang J, Walls J, Koss M, Ferrans V, Travis W 1996 Association of p53 and WAF1 expression with apoptosis in diffuse alveolar damage. Am J Pathol 149:531-538

7. Berthiaume Y, Lesur O, Dagenais A 1999 Treatment of adult respiratory distress syndrome: plea for rescue therapy of the alveolar epithelium. Thorax 54:150-160

8. Fink MP 2001 Prostaglandins and sepsis: still a fascinating topic despite almost 40 years of research. Am J Physiol Lung Cell Mol Physiol 281:L534-L536

9. Vane JR, Mitchell JA, Appleton I, Tomlinson A, Bishop-Bailey D, Croxtall J, Willoughby DA 1994 Inducible isoforms of cyclooxygenase and nitric-oxide synthase in inflammation. Proc Natl Acad Sci U S A 91:2046-2050

10. Groeneveld AB 2002 Vascular pharmacology of acute lung injury and acute respiratory distress syndrome. Vascul Pharmacol 39:247-256

11. Amann R, Schuligoi R, Peskar BA 1999 Eicosanoid release in the endotoxin-primed isolated perfused rat lung and its pharmacological modification. Inflamm Res 48:632-636

12. Downey GP, Gumbay RS, Doherty DE, LaBrecque JF, Henson JE, Henson PM, Worthen GS 1988 Enhancement of pulmonary inflammation by PGE2: evidence for a vasodilator effect. J Appl Physiol 64:728-741

13. Chang HC, Weng CF 2001 Cyclooxygenase-2 level and culture conditions influence NS398-induced apoptosis and caspase activation in lung cancer cells. Oncol Rep $8: 1321-1325$

14. Sanchez-Alcazar JA, Bradbury DA, Pang L, Knox AJ 2003 Cyclooxygenase (COX) inhibitors induce apoptosis in non-small cell lung cancer through cyclooxygenase independent pathways. Lung Cancer 40:33-44

15. Reddy RC, Chen GH, Tateda K, Tsai WC, Phare SM, Mancuso P, Peters-Golden M, Standiford TJ 2001 Selective inhibition of COX-2 improves early survival in murine endotoxemia but not in bacterial peritonitis. Am J Physiol Lung Cell Mol Physiol 281:L537-L543

16. Gilroy DW, Tomlinson A, Willoughby DA 1998 Differential effects of inhibitors of cyclooxygenase (cyclooxygenase 1 and cyclooxygenase 2) in acute inflammation. Eur J Pharmacol 355:211-217

17. Lukkarinen HP, Laine J, Kaapa PO 2003 Lung epithelial cells undergo apoptosis in neonatal respiratory distress syndrome. Pediatr Res 53:254-259 
18. Lukkarinen H, Laine J, Lehtonen J, Zagariya A, Vidyasagar D, Aho H, Kaapa P 2004 Angiotensin II receptor blockade inhibits pneumocyte apoptosis in experimental meconium aspiration. Pediatr Res 55:326-333

19. Grisham MB, Benoit JN, Granger DN 1990 Assessment of leukocyte involvement during ischemia and reperfusion of intestine. Methods Enzymol 186:729-742

20. Lukkarinen HP, Laine J, Aho H, Zagariya A, Vidyasagar D, Kaapa PO 2005 Angiotensin II receptor inhibition prevents pneumocyte apoptosis in surfactantdepleted rat lungs. Pediatr Pulmonol 39:349-358

21. Grassme H, Kirschnek S, Riethmueller J, Riehle A, Kürthy Gv, Lang F, Weller M, Gulbins E 2001 Response: role of apoptosis in Pseudomonas aeruginosa pneumonia. Science 294:1783

22. Schittny JC, Djonov V, Fine A, Burri PH 1998 Programmed cell death contributes to postnatal lung development. Am J Respir Cell Mol Biol 18:786-793

23. Kasper M, Rudolf T, Verhofstad AA, Schuh D, Muller M 1993 Heterogeneity in the immunolocalization of cytokeratin-specific monoclonal antibodies in the rat lung: evaluation of three different alveolar epithelial cell types. Histochemistry 100:65-71

24. Holopainen R, Aho H, Laine J, Halkola L, Kaapa P 1999 Nitric oxide inhalation inhibits pulmonary apoptosis but not inflammatory injury in porcine meconium aspiration. Acta Paediatr 88:1147-1155

25. Cuzzocrea S, Mazzon E, Sautebin L, Dugo L, Serraino I, De Sarro A, Caputi AP 2002 Protective effects of Celecoxib on lung injury and red blood cells modification induced by carrageenan in the rat. Biochem Pharmacol 63:785-795

26. Saito T, Rodger IW, Hu F, Robinson R, Huynh T, Giaid A 2004 Inhibition of COX pathway in experimental myocardial infarction. J Mol Cell Cardiol 37:71-77

27. Masferrer JL, Zweifel BS, Manning PT, Hauser SD, Leahy KM, Smith WG, Isakson PC, Seibert K 1994 Selective inhibition of inducible cyclooxygenase 2 in vivo is antiinflammatory and nonulcerogenic. Proc Natl Acad Sci U S A 91:3228-3232

28. Dowd NP, Scully M, Adderley SR, Cunningham AJ, Fitzgerald DJ 2001 Inhibition of cyclooxygenase-2 aggravates doxorubicin-mediated cardiac injury in vivo. J Clin Invest 108:585-590

29. Ermert L, Ermert M, Merkle M, Goppelt-Struebe M, Duncker HR, Grimminger F, Seeger W 2000 Rat pulmonary cyclooxygenase-2 expression in response to endo- toxin challenge: differential regulation in the various types of cells in the lung. Am J Pathol 156:1275-1287

30. Fukunaga K, Kohli P, Bonnans C, Fredenburgh LE, Levy BD 2005 Cyclooxygenase 2 plays a pivotal role in the resolution of acute lung injury. J Immunol 174:5033-5039

31. Gilroy DW, Colville-Nash PR, Willis D, Chivers J, Paul-Clark MJ, Willoughby DA 1999 Inducible cyclooxygenase may have anti-inflammatory properties. Nat Med 5:698-701

32. Martin C, Wohlsen A, Uhlig S 2001 Changes in airway resistance by simultaneous exposure to TNF-alpha and IL-1beta in perfused rat lungs. Am J Physiol Lung Cell Mol Physiol 280:L595-L601

33. Bolli R, Shinmura K, Tang XL, Kodani E, Xuan YT, Guo Y, Dawn B 2002 Discovery of a new function of cyclooxygenase (COX)-2: COX-2 is a cardioprotective protein that alleviates ischemia/reperfusion injury and mediates the late phase of preconditioning. Cardiovasc Res 55:506-519

34. Vancheri C, Mastruzzo C, Sortino MA, Crimi N 2004 The lung as a privileged site for the beneficial actions of PGE 2 . Trends Immunol 25:40-46

35. de la Monte SM, Hutchins GM, Moore GW 1986 Respiratory epithelial cell necrosis is the earliest lesion of hyaline membrane disease of the newborn. Am J Patho 123:155-160

36. Duan WR, Garner DS, Williams SD, Funckes-Shippy CL, Spath IS, Blomme EA 2003 Comparison of immunohistochemistry for activated caspase-3 and cleaved cytokeratin 18 with the TUNEL method for quantification of apoptosis in histological sections of PC-3 subcutaneous xenografts. J Pathol 199:221-228

37. Castelao JE, Bart 3rd, RD DiPerna CA, Sievers EM, Bremner RM 2003 Lung cancer and cyclooxygenase-2. Ann Thorac Surg 76:1327-1335

38. Shinmura K, Tang XL, Wang Y, Xuan YT, Liu SQ, Takano H, Bhatnagar A, Bolli R 2000 Cyclooxygenase-2 mediates the cardioprotective effects of the late phase of ischemic preconditioning in conscious rabbits. Proc Natl Acad Sci U S A 97:1019710202

39. Martich GD, Danner RL, Ceska M, Suffredini AF 1991 Detection of interleukin 8 and tumor necrosis factor in normal humans after intravenous endotoxin: the effect of antiinflammatory agents. J Exp Med 173:1021-1024 